\title{
Compressive Deformation Behavior Modeling of AZ31 Magnesium Alloy at Elevated Temperature Considering the Strain Effect
}

\author{
Gh. A. Nourollahi, M. Farahani, A. Babakhani ${ }^{\text {b }}$,S. S. Mirjavadi ${ }^{\text {a* }}$ \\ ${ }^{a}$ School of Mechanical Engineering, College of Engineering, University of Tehran, Tehran, Iran \\ ${ }^{\mathrm{b}}$ College of Engineering, University of Tehran, Tehran, Iran
}

Received: December 23, 2012; Revised: May 29, 2013

\begin{abstract}
The true stress-strain data from isothermal hot compression tests, in the temperature range of $300-500{ }^{\circ} \mathrm{C}$ and strain rate of $0.001-0.1 \mathrm{~s}^{-1}$, were employed to study the flow behavior of AZ31 and to develop constitutive equation based on an Arrhenius-type equation. The flow stress increases with the decrease of deformation temperature and the increase of strain rate, which can be represented by Zener-Hollomon parameter in an exponential equation. The influence of strain was incorporated in the developed constitutive equation by considering the effect of strain on material constants. The results show that the proposed constitutive equations give a precise estimate for high temperature flow stress AZ31 alloy, which means it can be used for numerical simulation of hot deformation process and for choosing proper deformation parameter in engineering practice accurately.
\end{abstract}

Keywords: magnesium alloy, flow behavior, constitutive equations, numerical modeling

\section{Introduction}

To analyze the hot deformation processes (e.g. forging, rolling and etc.) it is necessary to describe the change in mechanical response under external loadings. This should be conducted in terms of constitutive equations which relate the stress and strain values to the related thermomechanical conditions of temperature and strain rate. In this regard, a number of previous researches have been devoted to assess such equations for conventionally hot worked magnesium alloys. Some have applied a power law equation to describe the relationship between stress and strain rate at low stresses ${ }^{1-5}$. Others have employed an exponential relationship at high stresses ${ }^{2,6}$. A phenomenological method was proposed by Sellars and McTegart ${ }^{7}$ where the flow stress is expressed by the hyperbolic laws in an Arrhenius-type equation, has also been applied ${ }^{8,9}$. Qin et al..$^{10}$ developed a model to determine the flow stress of magnesium alloy during hot deformation. Quan et al. ${ }^{11}$ predicted a constitutive model for the dynamic recrystallization evolution of AZ80 magnesium alloy based on stress-strain data. However, there are always some limitations for the original constitutive model. So, in order to accurately describe and predict the flow behaviors for the different metals or alloys, considerable amount of works had been done to modify this equation by considering the special effects of the forming processing parameters. Slooff et al. ${ }^{12}$ have noted that a straindependent parameter should be incorporated to correct the constitutive behavior. Some investigations have established the constitutive equations for various metals and alloys such as $9 \mathrm{Cr}-1 \mathrm{Mo}(\mathrm{P} 91)$ steel $^{13}$, aluminum alloys ${ }^{14-16}, \mathrm{~V} 150$ grade oil casing stee ${ }^{17}$, H62 brass alloy ${ }^{18}$ incorporating the effect of the strain. However it has not well documented in case of magnesium alloys yet.

*e-mail: s.mirjavadi@ut.ac.ir
The present work deals with developing a proper constitutive based model using hyperbolic sine equations considering the effect of strain. The main objective is to describe the high temperature flow behavior of AZ31 alloy, as the most common wrought $\mathrm{AZ}$ magnesium alloy series.

\section{Experimental Procedure}

The experimental material was AZ31 magnesium alloy (Mg-2.9Al-0.85Zn-0.3Mn, wt. \%) which was received as-hot rolled plates with $22 \mathrm{~mm}$ thickness. The cylindrical hot compression testing specimens were machined in the sizes of $\Phi 8 \times H 12 \mathrm{~mm}$. In all as-rolled specimens the deformation axis was selected to be parallel to the rolling direction. As was well-documented the rolled plates would have a texture with basal plane mainly parallel to normal direction. In the present work the deformation axis of the all specimens is normal to the basal planes. The isothermal hot compression tests were carried out at temperature range of $300-500{ }^{\circ} \mathrm{C}$ with initial strain rate of $0.001,0.01$ and $0.1 \mathrm{~s}^{-1}$. The specimens were first heated up to the deformation temperature and held isothermally for $5 \mathrm{~min}$, prior to straining. The specimens were then compressed to a true strain of 0.4 using an Instron-4208 universal testing machine, equipped with electrical resistance furnace, which can maintain temperature variation of $\pm 5 \mathrm{~K}$. This was followed by quenching them in water right after straining.

\section{Result and Discussion}

\subsection{Flow stress characteristics}

True stress-true strain curves obtained from the hot compression tests of the rolled specimens are presented in Figure 1. As is observed, the peak flow stress is sensitive 
to temperature and strain rate, with the peak flow stress being shifted to lower stresses and lower strains as the rate of deformation is reduced or the deformation temperature is increased. The related characteristics will be discussed in the following sections.

\subsection{Constitutive equations}

As is well established the correlation between the flow stress $(\sigma)$, temperature $(\mathrm{T})$ and strain rate $(\dot{\varepsilon})$, particularly at high temperatures, can be expressed by an Arrhenius type equation ${ }^{7}$. Moreover, the effects of temperature and strain rate on deformation behavior may also be represented by the Zener-Holloman parameter $(Z)$ in an exponent type equation ${ }^{19}$. These are mathematically expressed as:

$$
Z=\dot{\varepsilon} \exp \left(\frac{\mathrm{Q}}{\mathrm{RT}}\right)
$$

$$
\dot{\varepsilon}=\mathrm{AF}(\sigma) \exp \left(\frac{-\mathrm{Q}}{\mathrm{RT}}\right)
$$

where

$$
F(\sigma)=\left\{\begin{array}{cc}
\quad \sigma^{\mathrm{n}_{1}} & \alpha \sigma<0.8 \\
\exp (\beta \sigma) & \alpha \sigma<1.2 \\
{[\sinh (\alpha \sigma)]^{\mathrm{n}}} & \text { for all } \sigma
\end{array}\right.
$$

where $\mathrm{R}$ is the universal gas constant $\left(8.314 \mathrm{~J} \mathrm{~mole}^{-1} \mathrm{~K}^{-1}\right)$; $\mathrm{T}$ is the absolute temperature in $\mathrm{K}$; $\mathrm{Q}$ is the activation energy
$\left(\mathrm{kJ} . \mathrm{mol}^{-1}\right) ; \mathrm{A}, \beta, \mathrm{n}_{1}, \alpha$ and $\mathrm{n}$ are the materials constants, $\alpha=\beta / n_{1}$.

\subsection{Determination of materials constants}

True stress-true strain data from the compression tests at various processing conditions were employed to calculate the materials constants of the constitutive equations. The evaluation procedure of material constants at true strain of 0.2 as an example is as follows. For low and high stress levels, substituting the values of $\mathrm{F}(\sigma)$ in Equation 2 gives the following relationships, respectively:

$\dot{\varepsilon}=\mathrm{B} \sigma^{n_{1}}$

$\dot{\varepsilon}=\mathrm{C} \exp (\beta \sigma)$

where $\mathrm{B}$ and $\mathrm{C}$ are the material constants. Taking Logarithm of both sides of Equation 4 and 5 yields:

$\operatorname{In}(\sigma)=\frac{1}{n_{1}} \operatorname{In}(\dot{\varepsilon})-\frac{1}{n_{1}} \operatorname{In}(\mathrm{B})$

$\sigma=\frac{1}{\beta} \operatorname{In}(\dot{\varepsilon})-\frac{1}{\beta} \operatorname{In}(\mathrm{C})$

The value of $n_{1}$ and $\beta$ is obtained from the mean slope values of In $\sigma$ vs. In $\dot{\varepsilon}$ plot and $\sigma-$ In $\dot{\varepsilon}$ plot (Figure 2 ). For rolled microstructure, these values were found to be 6.66 and $0.2 \mathrm{MPa}^{-1}$. The value of $\alpha=\beta / \mathrm{n}_{1}$ was calculated to be $0.03 \mathrm{MPa}^{-1}$. These values are in good agreement with
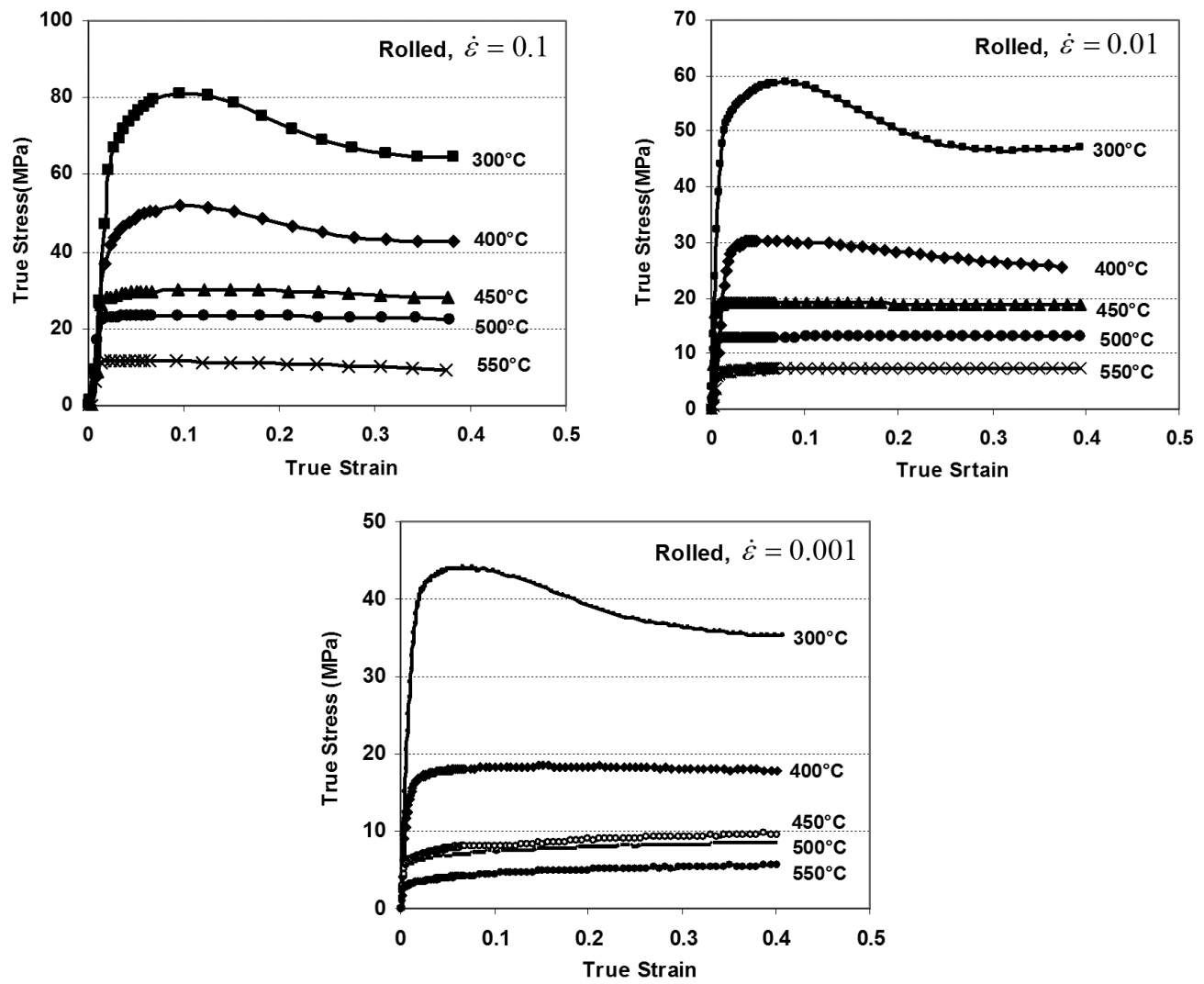

Figure 1. The typical true stress-strain curves of the experimental alloy obtained by hot compression tests. 
previous studies ${ }^{20-22}$. For all the strain levels, Equation 2 is rewritten as:

$$
\dot{\varepsilon}=\mathrm{A}[\sinh (\alpha \sigma)]^{\mathrm{n}} \exp \left(-\frac{\mathrm{Q}}{\mathrm{RT}}\right)
$$

Taking the logarithm of both sides of the above Equation gives:

$\ln [\sinh (\alpha \sigma)]=\frac{\operatorname{In} \dot{\varepsilon}}{\mathrm{n}}+\frac{\mathrm{Q}}{\mathrm{nRT}}-\frac{\mathrm{InA}}{\mathrm{n}}$

The slope of In $[\sinh ](\alpha \sigma)]$ vs. In $\dot{\varepsilon}$ yields $1 / n$ (Figure 3 ) and for a particular strain rate, differentiating Equation 8 gives:

$\mathrm{Q}=\operatorname{Rn} \frac{\mathrm{d}\{\ln [\sinh \alpha \sigma]\}}{\mathrm{d}\left(\frac{1}{\mathrm{~T}}\right)}$

Thus, the $Q$ parameter is determined from the slopes of In [ $\sinh \alpha \sigma]$ vs. $1 / \mathrm{T}$ (Figure 4 ), through averaging the values under different strain rates. Ln A is also easily found from the interception of In $[\sinh ](\alpha \sigma)]$ vs. In $\dot{\varepsilon}$. The activation energy is obtained to be in the range of $144-152 \mathrm{~kJ} / \mathrm{mol}$ for different strain values in the temperature range of $300-500{ }^{\circ} \mathrm{C}$. The calculated activation energy values are close to $\mathrm{Mg}$ self diffusion energy $\left(136 \mathrm{kj} / \mathrm{mol}^{[23,24]}\right)$. These

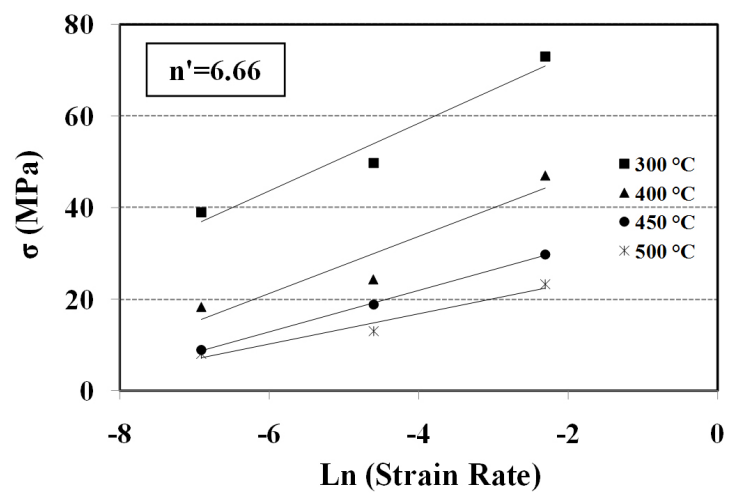

Figure 2. Relation between $\ln (\sigma)$ and $\ln (\dot{\varepsilon})$ of rolled AZ31 experimental alloy.

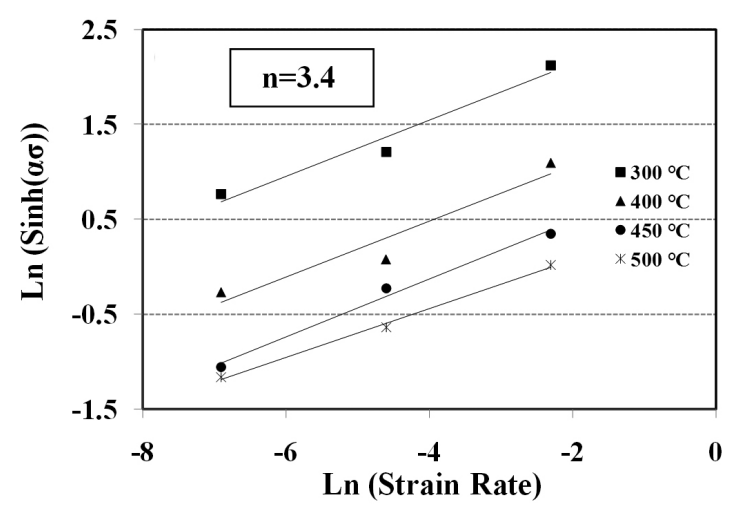

Figure 3. Relationship between $\ln [\sinh (\alpha \sigma)]$ and $\ln (\dot{\varepsilon})$ of rolled microstructure. obtained $Q$ values fall in the range that reported by previous researchers for hot deformation of magnesium alloys ${ }^{8,25}$. As is well known, some deviation in deformation activation energy is acceptable due to the nature of linear regression method used for acquiring the $Q$-value.

\subsection{Compensation of strain}

It has been recently shown that the deformation activation energy and material constants are strongly influenced by the strain ${ }^{14-18}$. Therefore, compensation of strain may have a significant effect on the accuracy of the flow stress prediction and should be taken into account in order to derive the proper constitutive equations. The influence of strain in the constitutive equation is incorporated by assuming that the activation energy $(Q)$ and material constants (i.e. $\mathrm{n}_{1}, \beta, \alpha, \mathrm{n}$ and $\ln \mathrm{A}$ ) are polynomial function of strains. In the present work, the values of the material constants were evaluated at various strains (in the range of 0.1-0.4) at the intervals of 0.05 , the corresponding curves of which are shown in Figure 5. These values were then employed to fit the polynomial function. A fifth order polynomial, as shown in Equation 11, was found to represent the influence of strain on the material constants with a very good correlation and generalization.

$$
\begin{aligned}
& \mathrm{Q}=\mathrm{C}_{0}+\mathrm{C}_{1 \varepsilon}+\mathrm{C}_{2} \varepsilon^{2}+\mathrm{C}_{3} \varepsilon^{3}+\mathrm{C}_{4} \varepsilon^{4}+\mathrm{C}_{5} \varepsilon^{5} \\
& \ln \mathrm{A}=\mathrm{D}_{0}+\mathrm{D}_{1} \varepsilon+\mathrm{D}_{2} \varepsilon^{2}+\mathrm{D}_{3} \varepsilon^{3}+\mathrm{D}_{4} \varepsilon^{4}+\mathrm{D}_{5} \varepsilon^{5} \\
& \alpha=\mathrm{E}_{0}+\mathrm{E}_{1} \varepsilon+\mathrm{E}_{2} \varepsilon^{2}+\mathrm{E}_{3} \varepsilon^{3}+\mathrm{E}_{4} \varepsilon^{4}+\mathrm{E}_{5} \varepsilon^{5} \\
& \mathrm{n}=\mathrm{F}_{0}+\mathrm{F}_{1} \varepsilon+\mathrm{F}_{2} \varepsilon^{2}+\mathrm{F}_{3} \varepsilon^{3}+\mathrm{F}_{4} \varepsilon^{4}+\mathrm{F}_{5} \varepsilon^{5}
\end{aligned}
$$

Once the materials constants are evaluated, the flow stress at a particular strain can be predicted. Accordingly, the constitutive equation that relates flow stress and ZenerHolloman parameter can be written in the following form (considering the Equation 1 and Equation 8):

$\sigma=\frac{1}{\alpha}\left\{\left(\frac{Z}{A}\right)^{\frac{1}{n}}+\left[\left(\frac{Z}{A}\right)^{\frac{2}{n}}+1\right]^{1 / 2}\right\}$

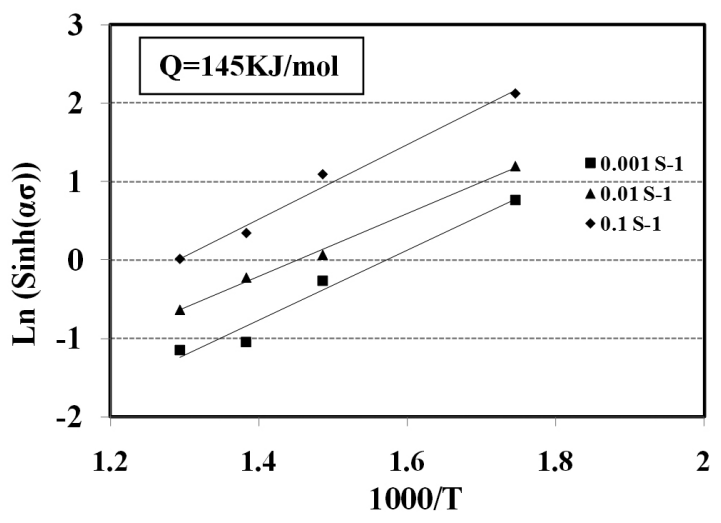

Figure 4. Relationship between $\ln [\sinh (\alpha \sigma)]$ and $1000 / \mathrm{T}$ of rolled microstructure. 


\subsection{Verification of constitutive equation}

The developed constitutive equation (considering the compensation of strain) has been verified through comparing the experimental and predicted data (Figure 6). As is observed a good agreement has been obtained between the
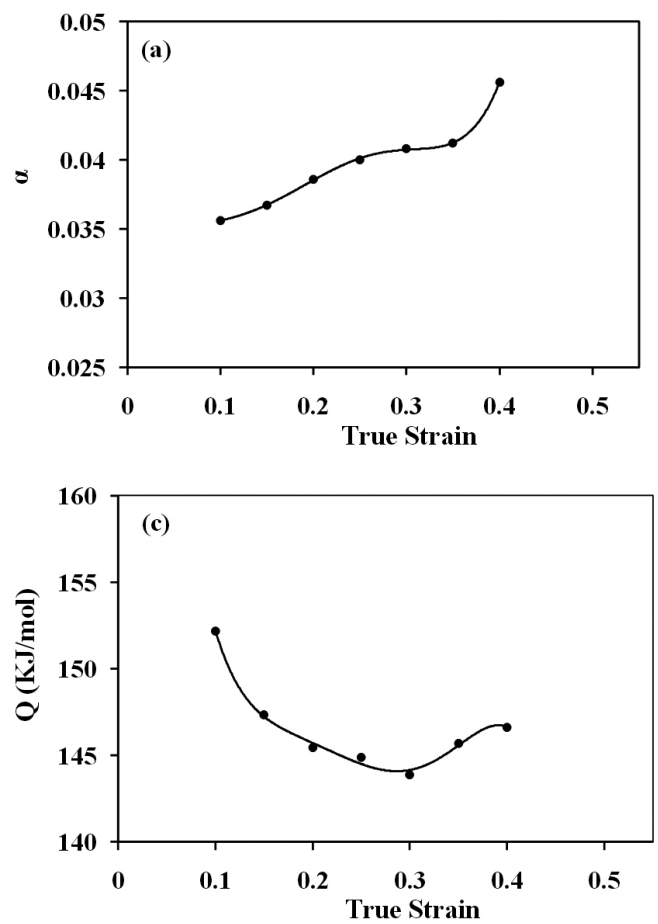

experimental and predicted stress values. The predictability of the constitutive equation is also quantified employing standard statistical parameters such as correlation coefficient (R) and average absolute relative error (AARE), as is shown in Figure 7. These are expressed as:
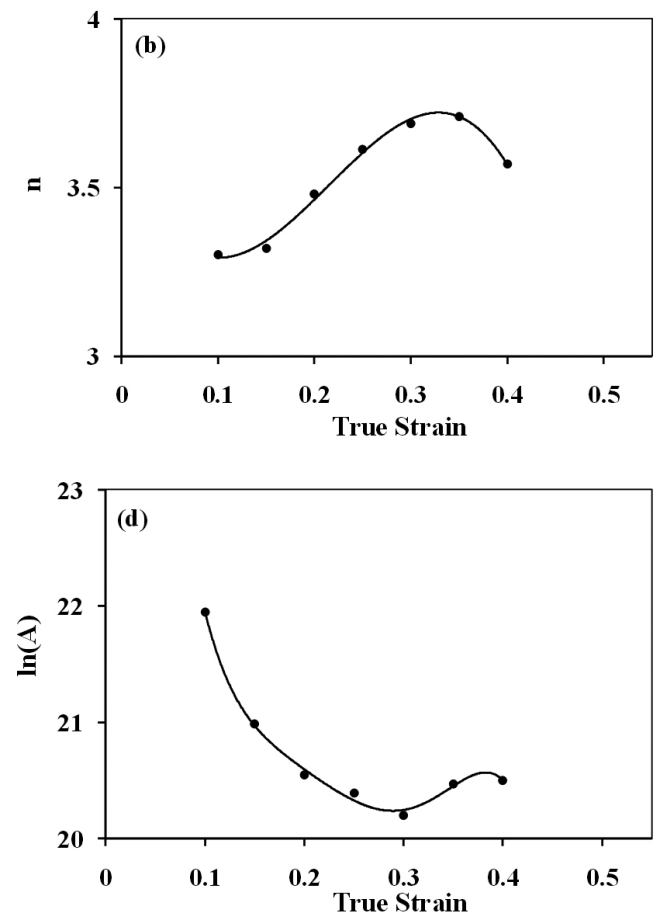

Figure 5. Variation of (a) $\alpha$ (b) n (c) Q and (d) ln A with true strain for rolled microstructure.
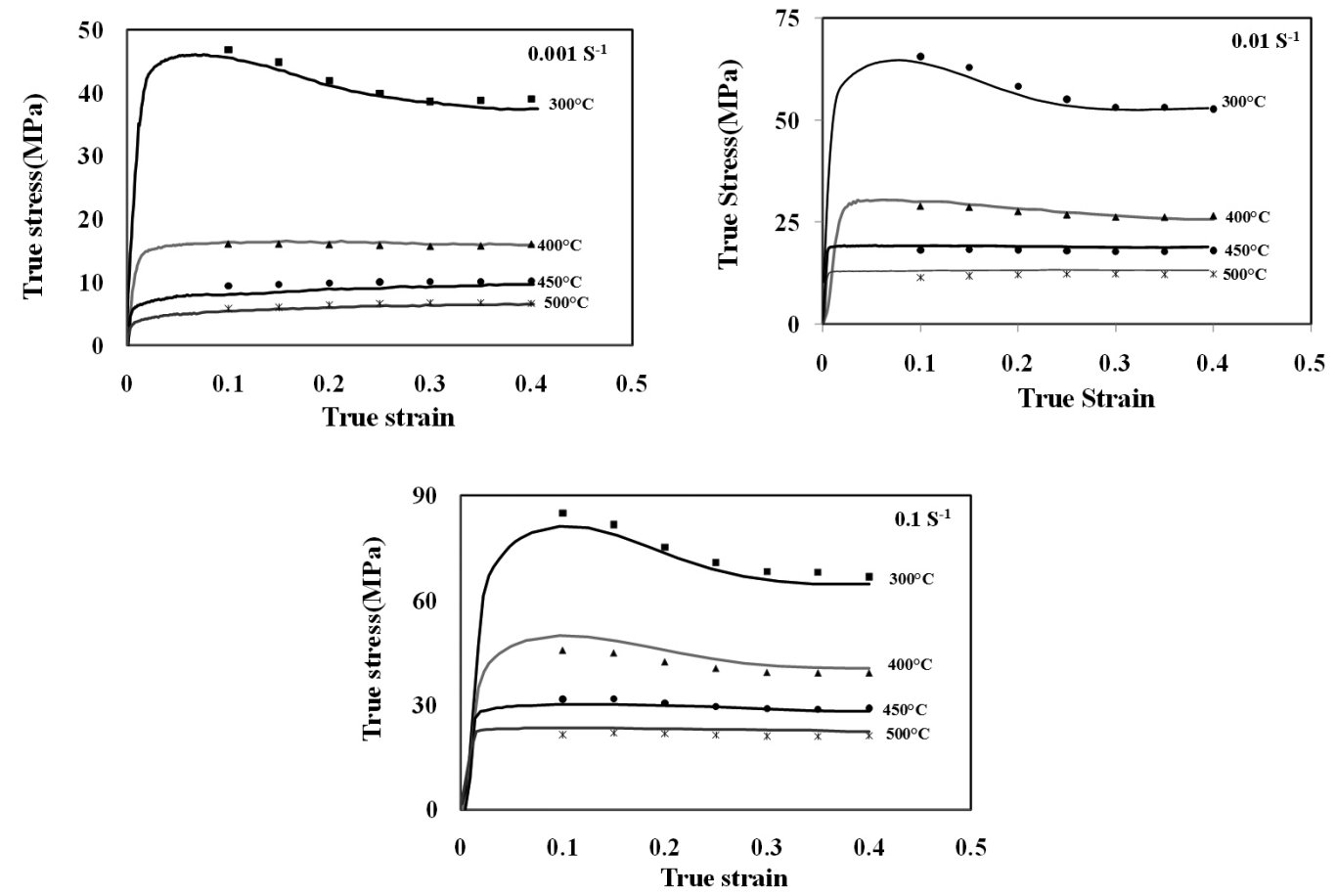

Figure 6. Comparison between the experimental and predicted flow stress at different strain rate for Rolled initial microstructure. 


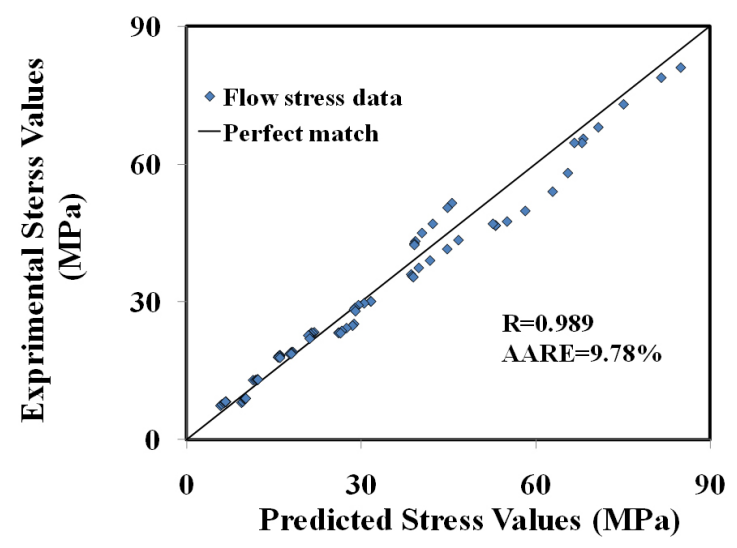

Figure 7. The correlation between the experimental and predicted flow stress data from the proposed constitutive equation over the entire range of strain, strain rate and temperature.

$$
\begin{aligned}
& \mathrm{R}=\frac{\sum_{\mathrm{i}=1}^{\mathrm{N}}\left(\mathrm{E}_{\mathrm{i}}-\overline{\mathrm{E}}\right)\left(\mathrm{P}_{\mathrm{i}}-\overline{\mathrm{P}}\right)}{\sqrt{\sum_{\mathrm{i}=1}^{\mathrm{N}}\left(\mathrm{E}_{\mathrm{i}}-\overline{\mathrm{E}}\right)^{2} \sum_{\mathrm{i}=1}^{\mathrm{N}}\left(\mathrm{P}_{\mathrm{i}}-\overline{\mathrm{P}}\right)^{2}}} \\
& \operatorname{AARE}(\%)=\frac{1}{N} \sum_{i=1}^{N}\left|\frac{E_{i}-P_{i}}{E_{i}}\right| \times 100
\end{aligned}
$$

where $\mathrm{E}$ is the experimental finding and $\mathrm{P}$ is the predicted value obtained from the constitutive equation. The $\bar{E}$ and $\bar{P}$ are the mean values of $\mathrm{E}$ and $\mathrm{P}$, respectively. The $\mathrm{N}$ is the number of data which were employed in the investigation. The correlation coefficient is a commonly used statistical parameter and provides information about the strength of linear relationship between the observed and the calculated

\section{References}

1. Changizian P, Zarei-Hanzaki A and Abedi HR. On the recrystallization behavior of homogenized AZ81 magnesium alloy: The effect of mechanical twins and $\gamma$ precipitates. Materials Science and Engineering: A. 2012; 558: 44-51. http:// dx.doi.org/10.1016/j.msea.2012.07.054

2. Abedi HR, Zarei-Hanzaki A and Khoddam S. Effect of $\gamma$ precipitates on the cavitation behavior of wrought AZ31 magnesium alloy. Materials \& Design. 2011; 32:2181-2190. http://dx.doi.org/10.1016/j.matdes.2010.11.029

3. Barnett MR. Influence of deformation conditions and texture on the high temperature flow stress of magnesium AZ31. Journal of Light Metals. 2001; 1:167-177. http://dx.doi.org/10.1016/ S1471-5317(01)00010-4

4. Beer AG and Barnett MR. Magnesium Technology 2002. Seattle: TMS; 2002. p. 193-198.

5. Huang GJ,Wang LY, Huang GS and Pan FS. Dynamic Recrystallization and Microstructure Evolution in AZ31 Magnesium Alloy during Thermomechanical Processing. Materials Science Forum. 2005; 488-489:215-218. http:// dx.doi.org/10.4028/www.scientific.net/MSF.488-489.215

6. Takuda H, Fujimoto H and Hatta N. Modelling on flow stress of $\mathrm{Mg}-\mathrm{Al}-\mathrm{Zn}$ alloys at elevated temperatures. Journal of values. Sabokpa et al. ${ }^{25}$ has shown that due to the tendency of the model/equation to be biased towards higher or lower values, the higher value of $\mathrm{R}$ does not necessarily indicate a better correlation. Thus, the AARE is computed through a term-by-term comparison of the relative error and therefore is an unbiased statistical parameter to measure the predictability of a model/equation ${ }^{26}$. The value of $\mathrm{R}$ and AARE was found to be 0.989 and $9.78 \%$, which shows that the proposed deformation constitutive equation gives an accurate and precise estimate of the flow stress.

\section{Conclusion}

The high temperature deformation behavior of wrought AZ31 magnesium alloy has been investigated by performing isothermal hot compression tests. Based on the experimental stress-strain data, constitutive analysis of AZ31 was carried out. The following conclusions can be drawn:

- Within the range of experiment, the flow stress of AZ31 increases with the increase of strain rate and the decrease of deformation temperature. The influence of strain was incorporated in the constitutive equation by considering the effect of strain on material constants (i.e. „, n, Q and $\ln$ A). A 5th order polynomial was used to represent the influence of strain on these material constants with good correlation;

- The flow stress can be predicted precisely using the constitutive equation (considering the compensation of strain) under the tested deformation conditions. The average absolute relative error associated with the prediction for the whole temperature and strain rate range was $9.78 \%$ and the correlation coefficient was 0.989 for rolled structure.
Materials Processing Technology. 1998; 80-81:513-516. http:// dx.doi.org/10.1016/S0924-0136(98)00154-X

7. Sellars CM and Tegart McG. On the mechanism of hot deformation. Acta Metallurgica. 1966; 14:1136-1138. http:// dx.doi.org/10.1016/0001-6160(66)90207-0

8. Yu K, Li W, Zhao J, Ma Z, Wang R. Plastic deformation behaviors of a Mg-Ce-Zn-Zr alloy. Scripta Materialia. 2003; 48:1319-1323. http://dx.doi.org/10.1016/S13596462(03)00046-0

9. Abedi HR, Zarei-Hanzaki A, Fatemi-Varzaneh SM and Roostaei A. The semi-solid tensile deformation behavior of wrought AZ31 magnesium alloy Materials \& Design. 2010; 31:4386-4391. http://dx.doi.org/10.1016/j.matdes.2010.05.004

10. Qin Y-J, Pan Q-L, He Y-B, Li W-B, Liu X-Y and Fan X. Modeling of flow stress for magnesium alloy during hot deformation. Materials Science and Engineering: A. 2010; 527:2790-2797. http://dx.doi.org/10.1016/j.msea.2010.01.035

11. Quan GZ, Shi Y, Wang YX, Kang BS, Ku TW and Song WJ. Constitutive modeling for the dynamic recrystallization evolution of AZ80 magnesium alloy based on stress-strain data. Materials Science and Engineering: A. 2011; 528:8051-8059. http://dx.doi.org/10.1016/j.msea.2011.07.064

12. Slooff FA, Zhou J, Duszczyk J and Katgerman L. Constitutive analysis of wrought magnesium alloy $\mathrm{Mg}-\mathrm{A} 14-\mathrm{Zn} 1$. Scripta 
Materialia. 2007; 57:759-762. http://dx.doi.org/10.1016/j. scriptamat.2007.06.023

13. Samantaray D, Mandal S and Bhaduri AK. Constitutive analysis to predict high-temperature flow stress in modified $9 \mathrm{Cr}-1 \mathrm{Mo}$ (P91) steel. Materials and Design. 2010; 31:981-984. http:// dx.doi.org/10.1016/j.matdes.2009.08.012

14. Lin YC, Xia YC, Chen XM and Chen MS. Constitutive descriptions for hot compressed 2124-T851 aluminum alloy over a wide range of temperature and strain rate. Computational Materials Science. 2010; 50:227-233. http:// dx.doi.org/10.1016/j.commatsci.2010.08.003

15. Li W, Li H, Wang Z and Zheng Z. Constitutive equations for high temperature flow stress prediction of $\mathrm{Al}-14 \mathrm{Cu}-7 \mathrm{Ce}$ alloy. Materials Science and Engineering: A. 2011; 528:4098-4103. http://dx.doi.org/10.1016/j.msea.2011.01.076

16. Gan CL, Xue YD and Wang MJ. Prediction of the flow stress of Al6061 at hot deformation conditions. Materials Science and Engineering: A. 2011; 528:4199-4203. http://dx.doi. org/10.1016/j.msea.2011.02.004

17. Li H-Y, Li Y-H, Wei D-D, Liu J-J and Wang X-F. Constitutive equation to predict elevated temperature flow stress of V150 grade oil casing steel. Materials Science and Engineering: A. $2011 ; 530: 367-372$. http://dx.doi.org/10.1016/j. msea.2011.09.097

18. Xiao Y-H, Guo C and Guo X-Y. Constitutive modeling of hot deformation behavior of H62 brass. Materials Science and Engineering: A. 2011; 528:6510- 6518. http://dx.doi. org/10.1016/j.msea.2011.04.090

19. Zener C and Hollomon H. Effect of Strain Rate Upon Plastic Flow of Steel. Journal of Applied Physics. 1944; 15:22-32. http://dx.doi.org/10.1063/1.1707363
20. Changizian P, Zarei-Hanzaki A and Roostaei AA. The high temperature flow behavior modeling of AZ81 magnesium alloy considering strain effects. Materials \& Design. 2012; 39: 384-389. http://dx.doi.org/10.1016/j.matdes.2012.02.049

21. Ravi Kumar NV, Blandin JJ, Desrayaud C, Montheillet F and Suery M. Grain refinement in AZ91 magnesium alloy during thermomechanical processing. Materials Science and Engineering: A. 2003; 359:150-157. http://dx.doi.org/10.1016/ S0921-5093(03)00334-4

22. Spigarelli S, Cabibbo M, Evangelista E, Talianker M and Esersky V. Analysis of the creep behaviour of a thixoformed AZ91 magnesium alloy. Materials Science and Engineering: A. 2000; 289:172. http://dx.doi.org/10.1016/ S0921-5093(00)00911-4

23. Frost HJ and Ashby MF. Deformation, DeformationMechanism Maps. Sydney: Pergamon Press; 1982.

24. Barnett MR, Atwell D and Beer AG. Effect of Grain Size on the Deformation and Dynamic Recrystallization of Mg-3Al1Zn. Materials Science Forum. 2004; 467-470:435-440. http:// dx.doi.org/10.4028/www.scientific.net/MSF.467-470.435

25. Sabokpa O, Zarei-Hanzaki A, Abedi HR and Haghdadi $\mathrm{N}$. Artificial neural network modelling to predict the high temperature flow behavior of an AZ81 magnesium alloy. Materials \& Design. 2012; 39:390-396. http://dx.doi. org/10.1016/j.matdes.2012.03.002

26. Srinivasulu $\mathrm{S}$ and Jain A. A comparative analysis of training methods for artificial neural network rainfall-runoff models. Applied Soft Computing. 2006; 6:295-306. http://dx.doi. org/10.1016/j.asoc.2005.02.002 